\title{
AC Loss Characterization of HTS Pancake and Solenoid Coils Carrying Nonsinusoidal Currents
}

\author{
Mohammad Yazdani-Asrami, Member, IEEE, Wenjuan Song, Xiaoze Pei, Min Zhang, and Weijia \\ Yuan
}

\begin{abstract}
Application of high temperature superconducting devices become promising in power networks, and transportation, including ship, train and electric aircraft propulsion systems, with the advantages of light weight, compact size, and high efficiency, compared to conventional devices. In reality, electric networks either in grid or transportation propulsion system - are polluted with harmonics due to the widespread use of power electronic devices and nonlinear loads. It is essential to explore the dependency of harmonic AC losses of different coil configurations carrying non-sinusoidal current. We modelled and compared harmonic AC loss behaviors in three coil configurations, single pancake coil (SPC), double pancake coil (DPC) and solenoid coil (SNC), where SPC and SNC are wound by identical wire length and DPC has twice conductor number compared to SPC. The research work has been carried out by means of $\mathrm{H}$-formulation finite element method in a 2D axisymmetric modelling environment of COMSOL Multiphysics. We explored and reported AC losses in these three coil structures carrying nonsinusoidal current with the $3^{\text {rd }}$ and the $5^{\text {th }}$ harmonic orders, respectively, under different total harmonic distortion (THD) and fundamental current levels. It has been concluded that AC loss in these coils firstly decreases with the increase of the $3^{\text {rd }}$ harmonic content, when THD of the $3^{\text {rd }}$ harmonic $<0.2$; and increase with the increase of the $3^{\text {rd }}$ harmonic when THD >0.2. AC loss in coils monotonically increases with the increase of the $5^{\text {th }}$ harmonic, drastically. We found that AC loss in SPC carrying the $3^{\text {rd }}$ harmonic and the $5^{\text {th }}$ harmonic at different THD are more than 3.8 times of that in DPC; AC loss in SPC carrying either $3^{\text {rd }}$ or $5^{\text {th }}$ harmonics at different THD are around 4.5 times of that in SNC.
\end{abstract}

Index Terms - AC loss, $\boldsymbol{H}$ formulation, nonsinusoidal currents, single pancake coil, double pancake coil, solenoid coil.

\section{INTRODUCTION}

T ARGE scale applications of high temperature superconductor (HTS) in generators, motors, transformers, fault current limiters (FCLs) and superconducting magnetic energy storage (SMES) have been practically demonstrated and installed in power networks, or proposed for transportation propulsion systems of ship, train and electric aircraft [1-3]. AC loss estimation in superconducting coils/windings is one of the key aspects in design and development stage, in terms of efficiency constraints of these HTS applications. In reality,

Manuscript submitted at 17 December 2019, revised at 11 January 2020, accepted at 31 January 2020.

M. Yazdani-Asrami, M. Zhang, and W. Yuan are with Department of Electronic and Electrical Engineering, University of Strathclyde, Glasgow G1 1XW, U.K. (e-mails: m.yazdaniasrami@gmail.com, mohammad.yazdaniasrami@strath.ac.uk,min.zhang@strath.ac.uk,weijia.yuan@strath.ac.uk). power network is polluted with harmonics due to widespread use of power electronic-based speed control devices, non-linear loads, induction or arc furnaces as well as lighting systems [45]. On the other hand, AC/DC converters are utilized in the ship, train and electric aircraft propulsion systems which would supply the current to superconducting AC machines in them. Moreover, ripple exists along with sinusoidal current or magnetic field in some applications [6-8]. Therefore, superconducting coils will carry distorted currents in all of aforementioned cases and so then, it is critical to calculate accurate AC loss in HTS coils considering harmonic currents.

There are several published articles in literature, reporting the effect of harmonic components on AC loss in superconducting tape or coils, analytically or experimentally [6-19]. In [9], an analytical method based on Bean's model is presented in order to calculate the AC loss of superconducting strips carrying higher order harmonic currents. It has shown that $5 \%$ harmonic can increases the AC loss by $20 \%$. In [10], authors used critical state model for calculating AC loss numerically-analytically under $3^{\text {rd }}$ harmonic and concluded that at currents close to critical current, $5 \%$ third harmonic can increases the AC losses by $90 \%$. In [11], AC loss of a Bi2223 tape was measured experimentally under distorted current and magnetic field. In [12], AC loss of a racetrack coil has been measured under high frequency nonsinusoidal currents with trapezoidal and triangular waveform. In [13], finite element modelling (FEM) using T-A formulation has been implemented to calculate the AC loss of a superconducting power cable carrying harmonic current. In [14-15], AC loss of a circular HTS pancake coil carrying currents with saw-tooth, triangle, and square waveforms has been calculated and measured. The effect of harmonic amplitude and frequency on $\mathrm{AC}$ loss has been studied. In [16], AC loss in HTS current lead under an arbitrary nonsinusoidal current waveform has been measured. Authors proposed two different types of current leads and compared their AC loss under harmonics in order to find the efficient solution. In [17], effect of high order current harmonics on AC loss of a traction transformer winding have been studied. In [18], AC loss of HTS stack under nonsinusoidal currents have been calculated for FCL applications. The results shown that

W. Song and X. Pei are with the Department of Electronic \& Electrical Engineering, The University of Bath, Bath, BA2 7AY, U.K. (e-mails: ws603@bath.ac.uk,x.pei@bath.ac.uk). 
harmonic currents substantially increase the AC loss, which needs to be considered in design stage of FCLs.

Up to now, there is no literature comparing the effect of harmonic current order and amplitude on AC loss in different coil structures. In this paper, a 2D axisymmetric numerical model has been developed in COMSOL Multiphysics based on $H$ formulation to calculate AC loss of different types of coils under nonsinusoidal currents. AC loss results in single pancake coil and solenoid coil, wound by identical tape length, carrying current distorted by $3^{\text {rd }}$ and $5^{\text {th }}$ harmonics with different level of total harmonic distortion (THD) were calculated and compared. We investigated and compared AC losses in single and double pancake coils carrying harmonic components at different fundamental current and THD levels. The influence of pitch length on AC loss of solenoid coil is also studied.

\section{Calculation Method}

\section{A. H-formulation}

Finite element $(\mathrm{FE})$ calculation was carried out in a $2 \mathrm{D}$ axisymmetric model in COMSOL, by means of $H$ formulation. Structured mesh was implemented in superconductor region to achieve a faster computing speed [19]. There are two independent variables in model, $\boldsymbol{H}=\left[H_{r}, H_{\mathrm{z}}\right]^{\mathrm{T}}$, where $H_{\mathrm{r}}$ and $H_{\mathrm{z}}$ are radial and axial magnetic fields, respectively.

The E-J power law (1) was used to express the highly nonlinear relation of local electric field $E$ and local current density $J$ in superconducting area, as follows.

$$
E / J=\left(E_{0} / J_{c}(B)\right)\left(J / J_{c}(B)\right)^{n-1}
$$

Where $E_{0}=1 \mu \mathrm{V} / \mathrm{cm}, \mathrm{n}=25$ is the power factor constant derived from V-I characteristic, and $J_{\mathrm{c}}(B)$ is critical current density dependence on external magnetic field, here a modified Kim model was adopted, as expressed in (2). $J_{\mathrm{c} 0}$ is the self-field critical current density. The $\mathrm{k}, \alpha$, and $B_{0}$ are curve fitting parameters as $0.41,0.24$, and $41 \mathrm{mT}$, respectively $[18,20]$.

$$
J_{c}(\mathrm{~B})=J_{c 0}\left(1+\left(k^{2} B_{z}^{2}+B_{r}^{2}\right) / B_{0}^{2}\right)^{-\alpha}
$$

By combining Farady's law (3), Ampere's law (4), Ohm's law (5), and constitutive law (6), the governing equation (7) is derived, in the form of partial differential equation. By adding the two variables $H_{\mathrm{r}}$ and $H_{\mathrm{z}}$ into (7), we obtained (8).

$$
\begin{gathered}
\nabla \times \boldsymbol{E}=-\partial \boldsymbol{B} / \partial t \\
\nabla \times \boldsymbol{H}=\boldsymbol{J} \\
\boldsymbol{E}=\rho \boldsymbol{J} \\
\boldsymbol{B}=\mu_{0} \mu_{r} \boldsymbol{H} \\
\partial\left(\mu_{0} \mu_{r} \boldsymbol{H}\right) / \partial \mathrm{t}+\nabla \times(\rho \nabla \times \boldsymbol{H})=0
\end{gathered}
$$

$$
\left\{\begin{array}{c}
\mu_{0} \mu_{r} \frac{\partial H_{r}}{\partial t}-\frac{1}{r} \frac{\partial\left(r \rho\left(\frac{\partial H_{r}}{\partial z}-\frac{\partial H_{z}}{\partial r}\right)\right)}{\partial z}=0 \\
\mu_{0} \mu_{r} \frac{\partial H_{z}}{\partial t}+\frac{1}{r} \frac{\partial\left(r \rho\left(\frac{\partial H_{r}}{\partial z}-\frac{\partial H_{z}}{\partial r}\right)\right)}{\partial r}=0
\end{array}\right.
$$

Transport current at any time, $I_{\mathrm{t}}$, was given by the integration of current density at corresponding time, $J(t)$, on the crosssection area $\mathrm{S}$ of superconducting layer, as shown in (9):

$$
I_{t}=\int_{S} J(t) d S
$$

To impose an unequivocal transport current in the conductor, integral constraint is used, so that the current with different harmonic distortions can be specified by function of time. Transport AC loss of superconducting coil, with unit of $\mathrm{J} / \mathrm{m} /$ cycle, can be calculated by (10):

$$
Q=2 \int_{T / 2}^{T} \int_{S} \boldsymbol{E} \cdot \boldsymbol{J} \mathrm{d} S d t
$$

Where $\mathrm{T}$ is the period of one cycle of applied current.

\section{B. Finite element modelling of the three coils}

In order to explore the effect of harmonic distortion on $\mathrm{AC}$ loss of different coil structures, we modelled three coils, single pancake coil (SPC), double pancake coil (DPC) and solenoid coil (SNC), where SPC and SNC have identical wire length. All these coils are modelled with $4 \mathrm{~mm}$-wide SCS4050 SuperPower wire with specifications listed in Table I. Fig. 1 shows the schematic of three coils in modelling process. Rectangular air region was used. Inner diameter of all three coils is $80 \mathrm{~mm}$. Geometrical specifications of the coils are tabulated in Table II. Kapton tape was considered as insulation between two adjacent turns of coil in model and the thickness of Kapton, $t_{\text {kap }}$, is 100 $\mu \mathrm{m}$.

\begin{tabular}{lc}
\multicolumn{2}{c}{ Table I Specifications of HTS coated conductor } \\
\hline \hline Item & Value \\
\hline Manufacturer & SuperPower \\
Tape ID & SCS4050 \\
Width of conductor $\left(w_{\mathrm{sc}}\right), \mathrm{mm}$ & 4 \\
Thickness of conductor $\left(\mathrm{t}_{\mathrm{sc}}\right), \mathrm{mm}$ & 0.1 \\
Thickness of superconducting layer, $\mu \mathrm{m}$ & 1 \\
Substrate & Hastelloy \\
Thickness of substrate, $\mu \mathrm{m}$ & 50 \\
Stabilizer & Copper \\
Thickness of stabilizer, mm & 0.04 \\
Critical current $\left(\mathrm{I}_{\mathrm{c}}\right) @$ $77 \mathrm{~K}$, self-field, A & 86 \\
\hline \hline
\end{tabular}

Table II Geometrical specifications of three modelled HTS coils

\begin{tabular}{cccc}
\hline \hline Items & SPC & SNC & DPC \\
\hline Turn number & 5 & 5 & 10 \\
Inner diameter (D), m & 0.08 & 0.08 & 0.08 \\
Wire length, $\mathrm{m}$ & 0.63 & 0.63 & 1.28 \\
Thickness of Kapton, $\left(t_{\text {kap }}\right), \mu \mathrm{m}$ & 100 & 100 & 100 \\
\hline \hline
\end{tabular}




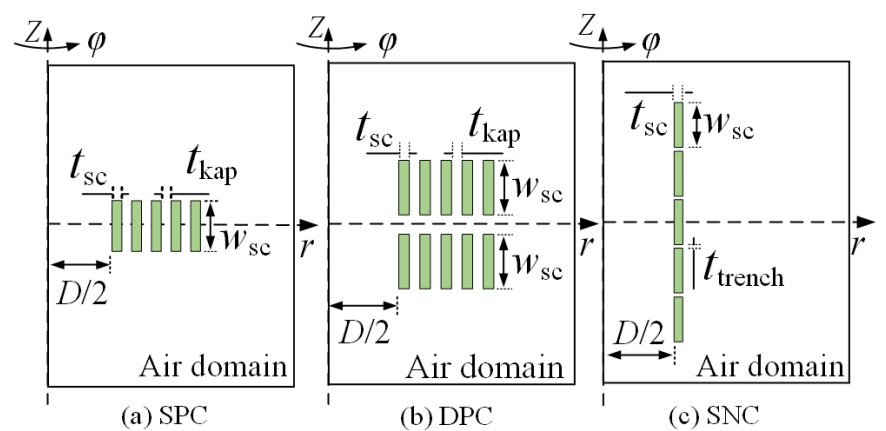

Fig. 1. Schematic of the 2D axisymmetric model of three coils. (a) SPC, single pancake coil (b) DPC, double pancake coil (c) SNC, solenoid coil. (not to scale)

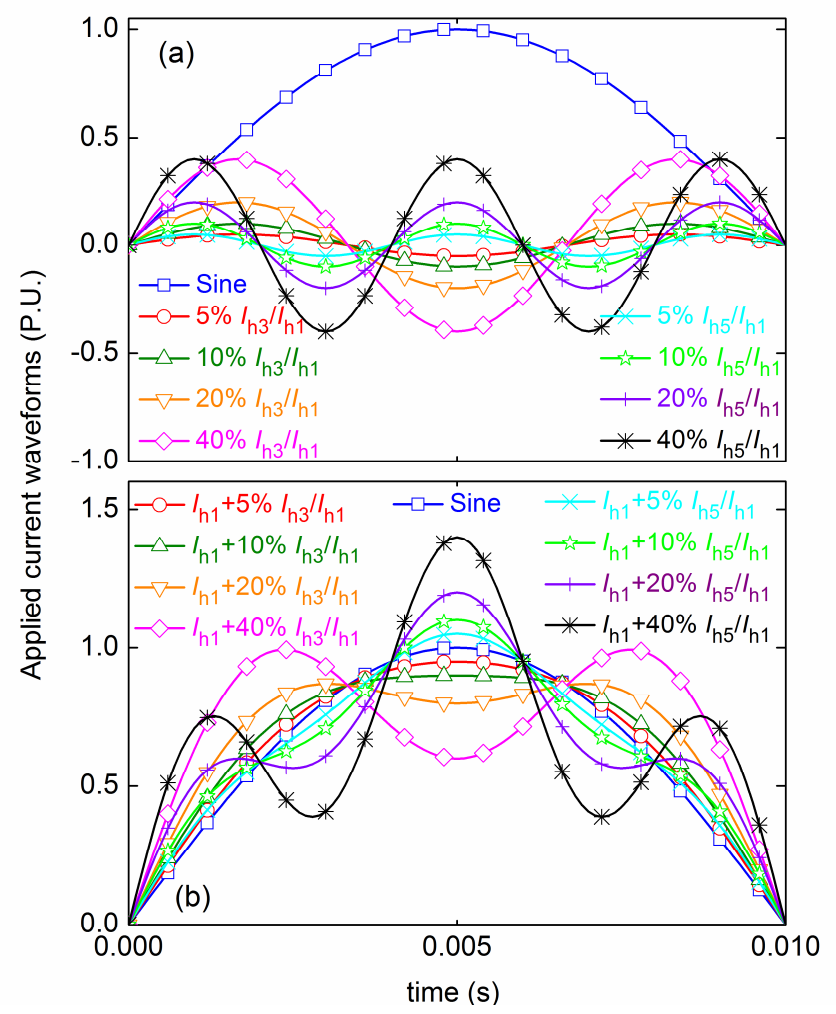

Fig. 2. Waveforms (half a cycle) of applied nonsinusoidal current flowing through HTS coils. (a) Waveforms of each harmonic component separately (b) Waveforms of resultant applied current distorted by different harmonic components.

\section{Nonsinusoidal current spectrum}

It is well-known that amplitude of harmonics decreases in higher orders and it is worthwhile to note that there is no even harmonics in symmetric electrical power network. Thus, the most significant harmonics after the fundamental order would be the $3^{\text {rd }}$ and the $5^{\text {th }}$ harmonics. Fig. 2(a) illustrates the fundamental sinusoidal current waveform per unit (p.u.), the $3^{\text {rd }}$ and $5^{\text {th }}$ harmonic current waveforms with amplitude of $I_{\mathrm{h} 3} / \mathrm{I}_{\mathrm{h} 1}$ and $I_{\mathrm{h} 5} / \mathrm{I}_{\mathrm{h} 1}$ ranging from $5 \%$ to $40 \%$. Here in this study, frequency of fundamental current harmonic is $50 \mathrm{~Hz} ; I_{\mathrm{h} 3}, I_{\mathrm{h} 5}, I_{\mathrm{h} 1}$ indicate the amplitude of the $3^{\text {rd }}$ harmonic current, the $5^{\text {th }}$ harmonic current and fundamental current, respectively. We define $I_{\mathrm{h} 3} 3 / \mathrm{I}_{\mathrm{h} 1}$ and $I_{\mathrm{h} 5} / \mathrm{I}_{\mathrm{h} 1}$ as total harmonic distortion, THD.

Fig. 2(b) plots the distorted current waveforms, by adding one harmonic current, $3^{\text {rd }}$ or $5^{\text {th }}$ order, with a certain amplitude to the fundamental current; i.e. the " $I_{\mathrm{h} 1}+5 \% I_{\mathrm{h} 3} / \mathrm{I}_{\mathrm{h} 1}$ " means the $3^{\text {rd }}$ harmonic with $I_{\mathrm{h} 3} / I_{\mathrm{h} 1}=5 \%$ added to the fundamental current.

When $I_{\mathrm{h} 3} / I_{\mathrm{h} 1}=5 \%, 10 \%$, and $20 \%$, the maximum amplitude (peak to peak) of distorted current carrying the $3^{\text {rd }}$ harmonic is smaller than that in sinusoidal current. But, more peaks occurred at $I_{\mathrm{h} 3} / \mathrm{I}_{\mathrm{h} 1}=40 \%$, as observe from Fig. 2(b).

The maximum magnitudes (peak to peak) of distorted currents carrying the $5^{\text {th }}$ harmonic are larger than that of sinusoidal current. With the increase of $I_{\mathrm{h} 5} / \mathrm{I}_{\mathrm{h} 1}$, the maximum value of distorted current increase accordingly.

It is worthy to point that the THD of distorted current carrying either the $3^{\text {rd }}$ or $5^{\text {th }}$ harmonic are considered as $5 \%$, $10 \%, 20 \%$ and $40 \%$ in simulations, which reasonably covers the THDs of both industrial and domestic nonlinear loads in real world applications.

\section{RESUltS AND DiscusSIONS}

In this section, simulation process for different case studies of nonsinusoidal current were presented. Then, the calculated nonsinusoidal AC loss results for different coil configurations were discussed. The nonsinusoidal AC losses are calculated at different THDs, carrying current levels, and different harmonic orders.

In this paper, all simulations were solved by a computer with these configurations: Intel Core i7-5500U $2.4 \mathrm{GHz}$ CPU 8 GB RAM.

\section{A. AC loss analysis in pancake coils carrying sinusoidal and} nonsinusoidal currents

Fig. 3(a) reports AC losses in SPC carrying nonsinusoidal currents with the $3^{\text {rd }}$ harmonic, as a function of $I_{\mathrm{h} 3} / \mathrm{I}_{\mathrm{h} 1}=0,5 \%$, $10 \%, 20 \%$, and $40 \%$, at $I_{\mathrm{h} 1} / I_{\mathrm{c}}=0.1,0.2,0.3,0.4$, and 0.5 , respectively. We observed that AC loss in SPC always reaches the minimum at $I_{\mathrm{h} 3} / \mathrm{I}_{\mathrm{h} 1}=20 \%$, when $I_{\mathrm{h} 1} / I_{\mathrm{c}}$ varies from 0.1 to 0.5 .

When $0 \%<\mathrm{I}_{\mathrm{h} 3} / \mathrm{I}_{\mathrm{h} 1}<20 \%$, AC loss in SPC decreases with the increase of the $3^{\text {rd }}$ harmonic content. When $20 \%<I_{\mathrm{h} 3} / \mathrm{I}_{\mathrm{h} 1}<40 \%$, $\mathrm{AC}$ loss in SPC increases with the increase of the $3^{\text {rd }}$ harmonic content. The AC losses at $I_{\mathrm{h} 3} / \mathrm{I}_{\mathrm{h} 1}=20 \%$ is relatively $40 \%$ less than value of sinusoidal loss at different carrying current levels.

When $I_{\mathrm{h} 3} / \mathrm{h}_{\mathrm{h} 1}=40 \%$, nonsinusoidal AC loss is about $5 \%$ higher than sinusoidal AC loss. It is worthy to note that at a certain $I_{\mathrm{h} 3} / \mathrm{I}_{\mathrm{h}}, \mathrm{AC}$ loss in SPC increases with the increase of $I_{\mathrm{h} 1} / I_{\mathrm{c}}$. Fig. 3(b) reports AC losses in SPC carrying nonsinusoidal currents with the $5^{\text {th }}$ harmonic, as a function of $I_{\mathrm{h} 3} / \mathrm{I}_{\mathrm{h} 1}=0,5 \%$, $10 \%, 20 \%$, and $40 \%$, at $I_{\mathrm{h} 1} / I_{\mathrm{c}}=0.1,0.2,0.3,0.4$, and 0.5 , respectively. AC loss in SPC carrying the $5^{\text {th }}$ harmonic increases monotonically with the increase of $I_{\mathrm{h} 5} / \mathrm{I}_{\mathrm{h} 1}$ ranging from $0 \%$ to $40 \%$, when $I_{\mathrm{h} 1} / I_{\mathrm{c}}$ varies from 0.1 to 0.5 . At a certain $I_{\mathrm{h} 5} / \mathrm{I}_{\mathrm{h} 1}$, AC loss in SPC increases with the increase of $I_{\mathrm{h} 1} / I_{\mathrm{c}}$, which is similar as when carrying the $3^{\text {rd }}$ harmonic. The nonsinusoidal AC loss caused by $5^{\text {th }}$ harmonic increases $16 \%$, $37 \%, 88 \%$, and $185 \%$ respect to sinusoidal AC loss, at $I_{\mathrm{h} 5} / \mathrm{I}_{\mathrm{h} 1}=$ $5 \%, 10 \%, 20 \%$, and $40 \%$, respectively.

Fig. 4(a) and 4(b) show instantaneous losses in SPC carrying $3^{\text {rd }}$ and $5^{\text {th }}$ harmonic currents with different THDs, respectively, 
at $\mathrm{I}_{\mathrm{h} 1} / \mathrm{I}_{\mathrm{c}}=30 \%$. AC loss is the integral of instantaneous loss over one period of applied current.

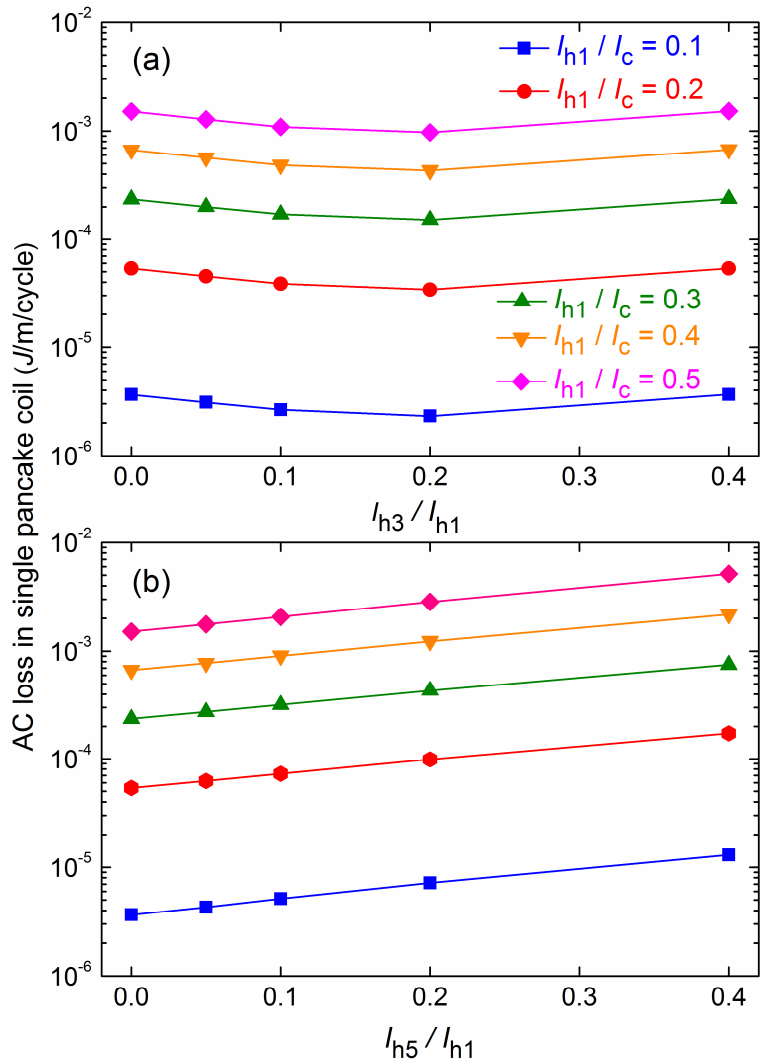

Fig. 3. AC loss results in SPC carrying harmonic current components at $I_{\mathrm{h} 1} / I_{\mathrm{c}}$ ranges from 0.1 to 0.5 . (a) carrying the $3^{\text {rd }}$ harmonic (b) carrying the $5^{\text {th }}$ harmonic

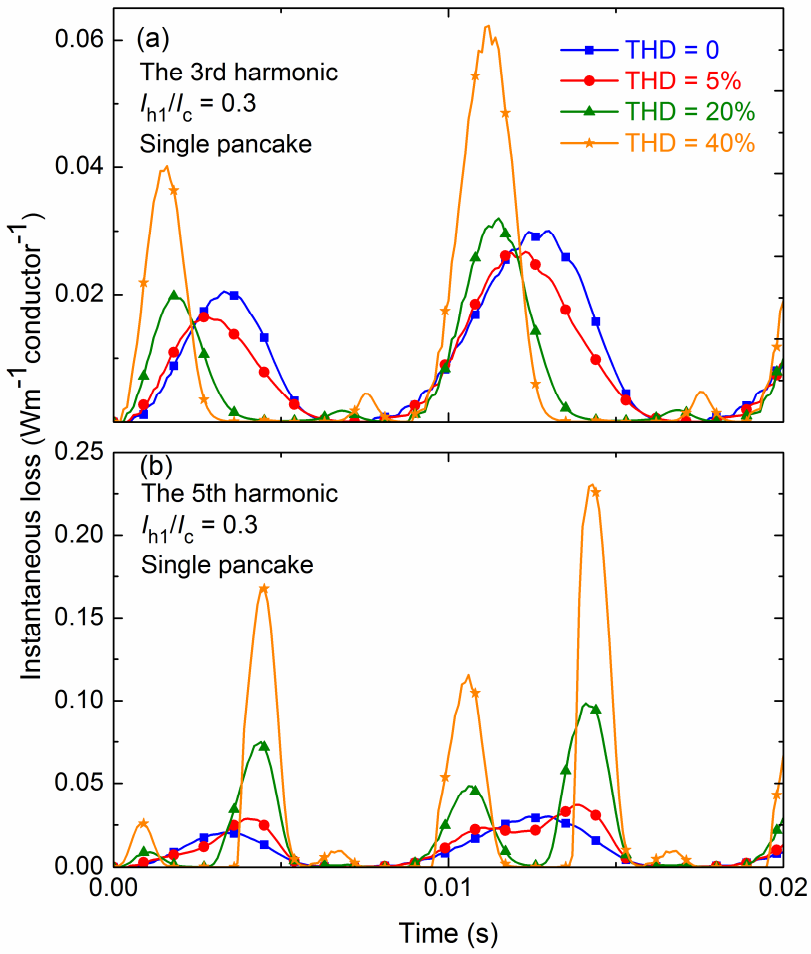

Fig. 4. Instantaneous loss in SPC carrying distorted current at $I_{\mathrm{h} 1} / I_{\mathrm{c}}=0.3$ and different THDs. (a) with $3^{\text {rd }}$ harmonic (b) with $5^{\text {th }}$ harmonic

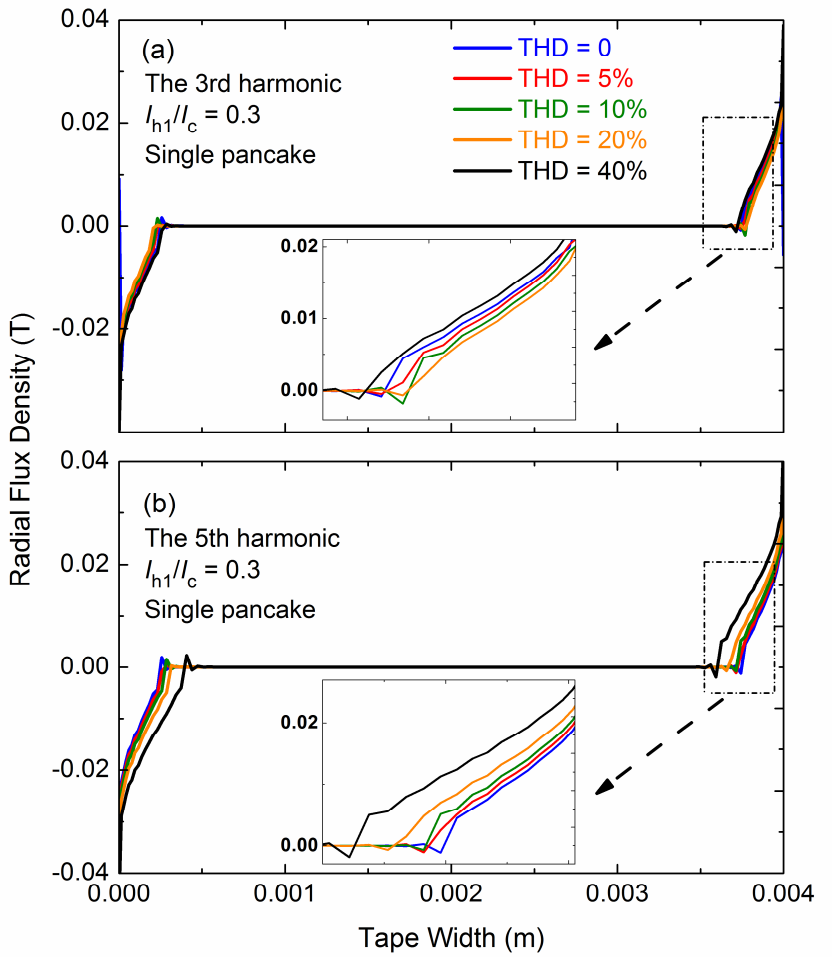

Fig. 5. Distribution of radial flux density along the width of inner most tape in SPC carrying distorted current at $I_{\mathrm{h} 1} / I_{\mathrm{c}}=30 \%$ and THD ranges from 0 to $40 \%$. (a) with the $3^{\text {rd }}$ harmonic (b) with the $5^{\text {th }}$ harmonic

In Fig. 4(a), the peaks of instantaneous loss in case of the $5^{\text {th }}$ harmonics are much higher than that with the $3^{\text {rd }}$ harmonics, i.e. it is $4 \mathrm{x}$ higher in average over different THDs. Two dominant peaks were observed in instantaneous loss profile resulted from distorted current containing the $3^{\text {rd }}$ harmonic, while there are three dominant peaks in the $5^{\text {th }}$ harmonic case. Another interesting observation is that the amplitude of peaks is always increasing with THD of distorted current in case of the $5^{\text {th }}$ harmonic. However, the minimum peaks of instantaneous loss in SPC carrying currents distorted by the $3^{\text {rd }}$ harmonics occur at $\mathrm{THD}=5 \%$, rather than $20 \%$. It is worthwhile to mention again that it is not the peak value of instantaneous loss which determines AC loss in coils, but the integral of instantaneous loss over a cycle. For example, the peak of instantaneous loss when current carrying the $3^{\text {rd }}$ harmonic with $\mathrm{THD}=20 \%$ is higher than that in sinusoidal current, but the integral of instantaneous loss carrying the $3^{\text {rd }}$ harmonic with $\mathrm{THD}=20 \%$ is smaller than that of sinusoidal current.

To further explain AC loss behavior in SPC carrying $3^{\text {rd }}$ and $5^{\text {th }}$ harmonics at different THD, radial magnetic flux density $\left(B_{\mathrm{r}}\right)$ and resistivity distribution along a hypothetical line crossing center of the innermost tape in SPC were plotted in Fig. 5 and Fig. 6, respectively, at $I_{\mathrm{h} 1} / \mathrm{I}_{\mathrm{c}}=30 \%$ and $t=0.015 \mathrm{~s}$. In Fig. 5(a), it has been observed that the order of penetration depth, $d_{\mathrm{p}}$, in innermost tape of SPC carrying distorted current by the $3^{\text {rd }}$

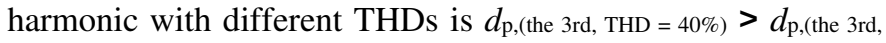

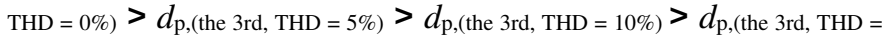
$20 \%$ ). For the $3^{\text {rd }}$ harmonic, penetration depth reaches the minimum when THD $=20 \%$, which shows good agreement with the AC loss behavior of nonsinusoidal current carrying $3^{\text {rd }}$ 
harmonic. In Fig. 5(b), the order of penetration depth, $d_{\mathrm{p}}$, in innermost tape of SPC carrying distorted current by the 5th harmonic with different THD is $d_{\mathrm{p} \text {,(the } 5 \text { th, THD }=40 \% \text { ) }}>d_{\mathrm{p} \text {,(the } 5 \text { th, THD }}$

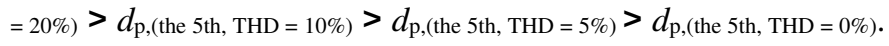
Again, the penetration depth of distorted current with $5^{\text {th }}$ harmonic at different THD agrees with AC loss behavior.

Resistivity of the superconducting layer of tape which is actually proportional to AC loss, must be higher in the tape ends, as it is depicted in the Fig. 6. In both Fig. 5 and Fig. 6, the radial flux density and resistivity at the tape ends increase by THD increment when current is distorted by $5^{\text {th }}$ harmonic, i.e. $\mathrm{B}_{\mathrm{r}}$ is much higher when carrying current contains $40 \% 5^{\text {th }}$ harmonic, compared with sinusoidal current, and therefore the resistivity of superconducting layer shows the same behavior pattern. But in case of distorted current with $3^{\text {rd }}$ harmonic, the $B_{r}$ and resistivity both decrease with THD increment.

Fig. 7(a) and 7(b) show nonsinusoidal AC losses versus THD in DPC carrying $3^{\text {rd }}$ and $5^{\text {th }}$ harmonics, respectively, at different carrying current levels. In Fig. 7(a), AC loss in DPC shows a similar trend to that in SPC carrying the $3^{\text {rd }}$ harmonic, i.e., AC loss in DPC caused by the $3^{\text {rd }}$ harmonic has a minimum at $\mathrm{THD}=20 \%$. However, in terms of the amplitude of AC loss, losses in the DPC is always about $3.5 \mathrm{x}$ to $4.5 \mathrm{x}$ higher than those of SPCs at $I_{\mathrm{h} 1} / I_{\mathrm{c}}$ ranging from 0.1 to 0.5 and THD ranging from $0 \%$ to $40 \%$. On the other hand, AC loss in DPC carrying $I_{\mathrm{h} 3} / \mathrm{h}_{\mathrm{h} 1}=$ $20 \%$ at any $I_{\mathrm{h}} / I_{\mathrm{c}}$ is about $65 \%$ of that carrying sinusoidal current. In Fig. 7(b), AC loss in DPC increases with the increase of the THD of the $5^{\text {th }}$ harmonic. Losses in DPC carrying the $5^{\text {th }}$ harmonic at THD $=5 \%, 10 \%, 20 \%$, and $40 \%$ have increased $16 \%, 36 \%, 84 \%$, and $224 \%$ compared to that carrying sinusoidal current, respectively.

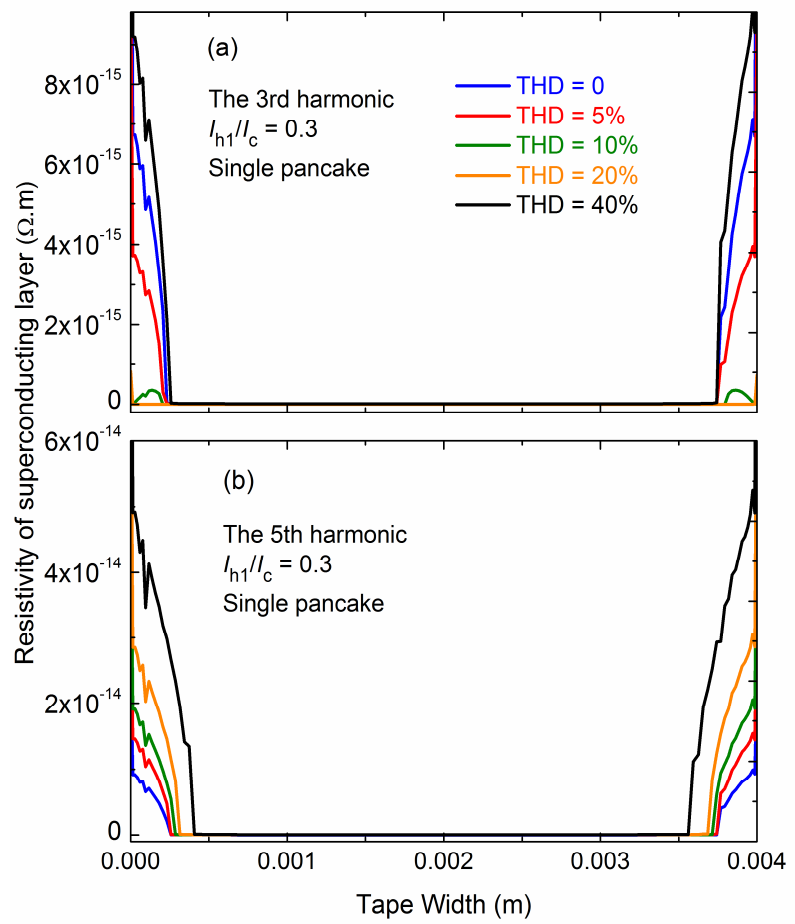

Fig. 6. Resistivity distribution across innermost tape in SPC carrying distorted current at $I_{\mathrm{h} 1} / I_{\mathrm{c}}=30 \%$ and THD ranges from 0 to $40 \%$. (a) with the $3^{\text {rd }}$ harmonic (b) with the $5^{\text {th }}$ harmonic

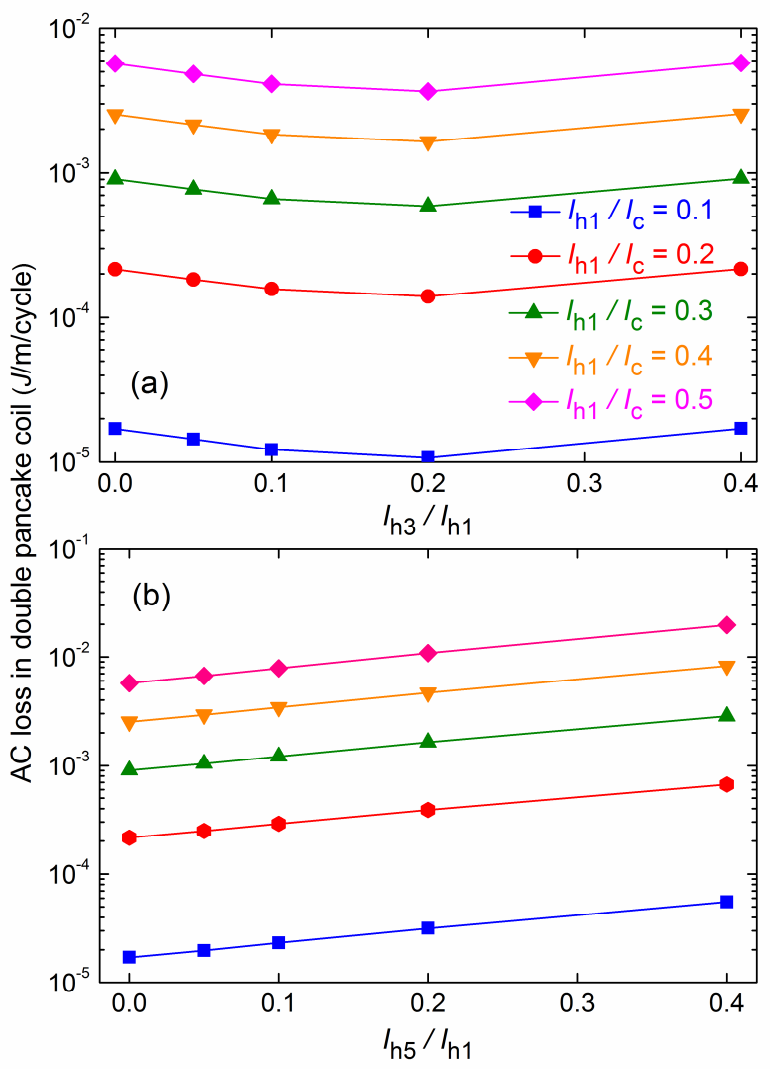

Fig. 7. AC loss results in DPC carrying harmonic current components versus THD at different $I_{\mathrm{h} 1} / I_{\mathrm{c}}$ ranges from 0.1 to 0.5 . (a) carrying the $3^{\text {rd }}$ harmonic (b) carrying the $5^{\text {th }}$ harmonic

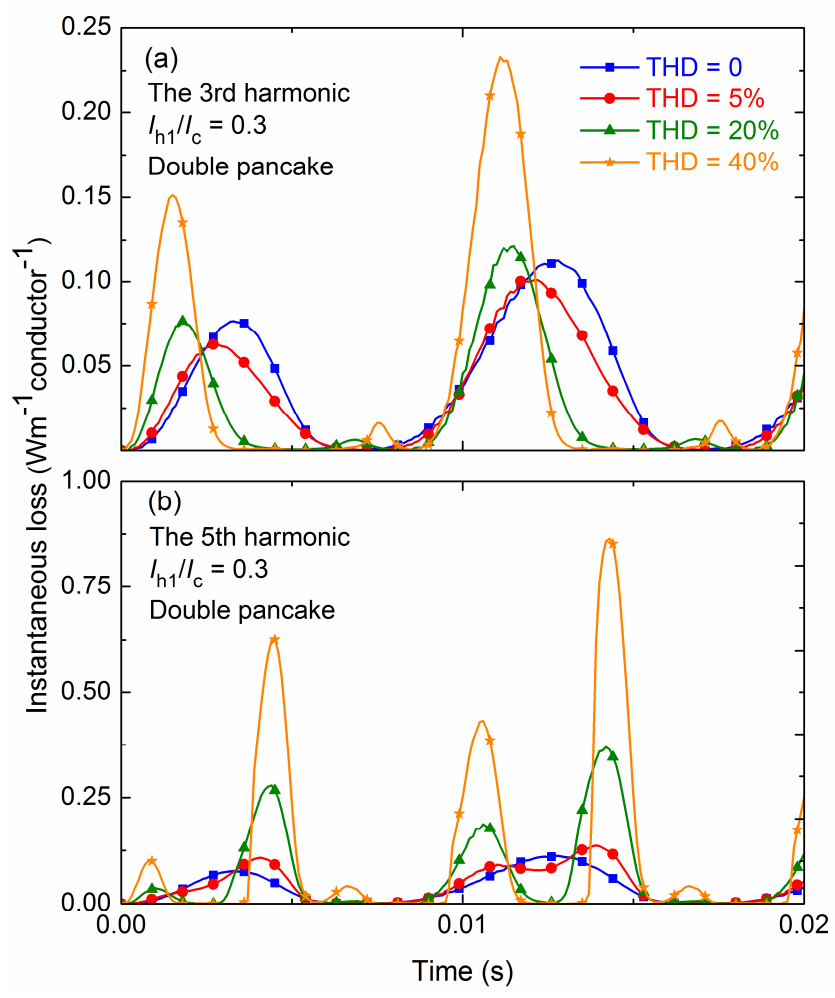

Fig. 8. Instantaneous AC loss in DPC carrying distorted current at $I_{\mathrm{h} 1} / I_{\mathrm{C}}=0.3$ and different THDs. (a) with $3^{\text {rd }}$ harmonic (b) with $5^{\text {th }}$ harmonic 
Fig. 8(a) and 8(b) report the instantaneous losses of DPC at $I_{\mathrm{h} 1} / I_{\mathrm{c}}=0.3$ and different THDs of the $3^{\text {rd }}$ and the $5^{\text {th }}$ harmonic during one period of applied current. There are two and three dominant peaks in instantaneous loss profiles of the $3^{\text {rd }}$ and the $5^{\text {th }}$ harmonics in Fig. 8(a) and 8(b), respectively, as well as sideband shorter peaks, which are all similar to that in SPC. In average, the peaks of instantaneous loss profile of the $5^{\text {th }}$ harmonic are $3 \mathrm{x}$ to $4 \mathrm{x}$ higher than $3^{\text {rd }}$ harmonics.

\section{B. AC loss analysis in SNC carrying sinusoidal and} nonsinusoidal currents

AC losses in SNC carrying sinusoidal current with trench length ranging from 0.5 to $2.5 \mathrm{~mm}$ at different $I_{\mathrm{h} 1} / I_{\mathrm{c}}$ were illustrated in Fig. 9. At a fixed specific trench length, AC loss in SNC increases when $I_{\mathrm{h} 1} / I_{\mathrm{c}}$ increases. On the other hand, AC loss decreases with the increase of trench length due to weaker superposition of radial magnetic field at the end part of the coil. It should be mentioned that trench length of SNC is fixed at 1 $\mathrm{mm}$ for modelling and calculation of $\mathrm{AC}$ loss in the rest of this paper.

Fig. 10(a) and 10(b) depict AC loss results versus THDs in SNC with $t_{\text {trench }}=1 \mathrm{~mm}$ carrying nonsinusoidal current, distorted by $3^{\text {rd }}$ and $5^{\text {th }}$ harmonics, respectively, while $I_{\mathrm{hl}} / I_{\mathrm{c}}$ ranges from 0.1 to 0.5 . When harmonic current (either the $3^{\text {rd }}$ or the 5th) and THD are fixed, AC loss in SNC increases with the increase of fundamental current amplitude, $I_{\mathrm{h} 1} / I_{\mathrm{c}}$. In Fig. 10(a), AC loss reaches the minimum when $I_{\mathrm{h} 3} / I_{\mathrm{h} 1}=0.2$, at any $I_{\mathrm{h} 1} / I_{\mathrm{c}}$ value. AC loss decreases with the increase of $I_{\mathrm{h} 3} / I_{\mathrm{h} 1}$, when $I_{\mathrm{h} 3} / I_{\mathrm{h} 1}$ $<0.2$. AC loss increases with the increase of $I_{\mathrm{h} 3} / I_{\mathrm{h} 1}$, when $0.2<$ $I_{\mathrm{h} 3} / I_{\mathrm{h} 1}<0.4$. AC loss performance of SNC carrying the $3^{\text {rd }}$ harmonic current is similar to that in a stack, as shown in [18]. AC losses in SNC carrying the $3^{\text {rd }}$ harmonic with $I_{\mathrm{h} 3} / I_{\mathrm{h} 1}=5 \%$, $10 \%, 20 \%$, and $40 \%$ are $83 \%, 70 \%, 59 \%$ and $101 \%$ of that in SNC carrying sinusoidal current, respectively. In Fig. 10(b), AC loss increases with the increment of $I_{\mathrm{h} 5} / I_{\mathrm{h} 1}$. This is due to the stronger radial magnetic field in the coil. While AC losses in SNC carrying the $5^{\text {th }}$ harmonic with $I_{\mathrm{h} 3} / I_{\mathrm{h} 1}=5 \%, 10 \%, 20 \%$, and $40 \%$ are $118 \%, 138 \%, 195 \%$ and $363 \%$ of that in SNC carrying sinusoidal current, respectively.

The instantaneous loss in the SNC under distorted currents with the $3^{\text {rd }}$ and the $5^{\text {th }}$ harmonics at $I_{\mathrm{h} 1} / I_{\mathrm{c}}=0.3$ are illustrated in Fig. 11(a) and 11(b), respectively.

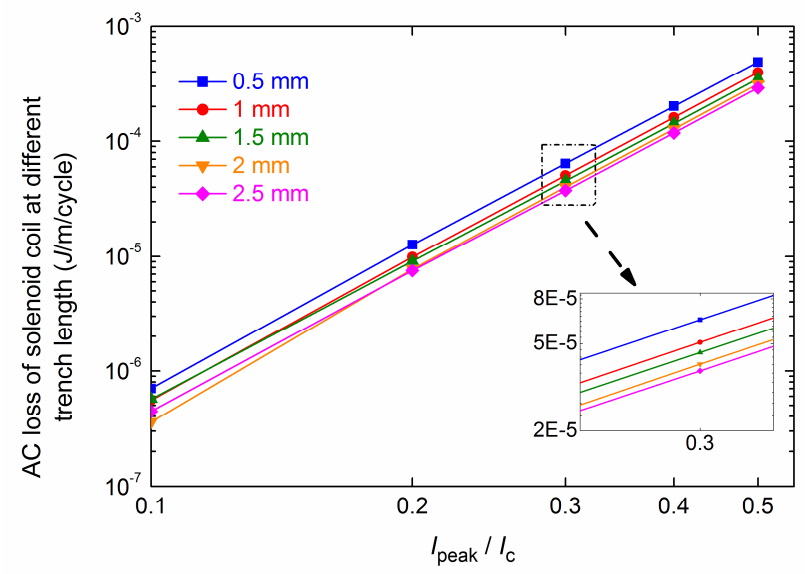

Fig. 9. AC losses versus carrying sinusoidal current in SNC at different trench lengths

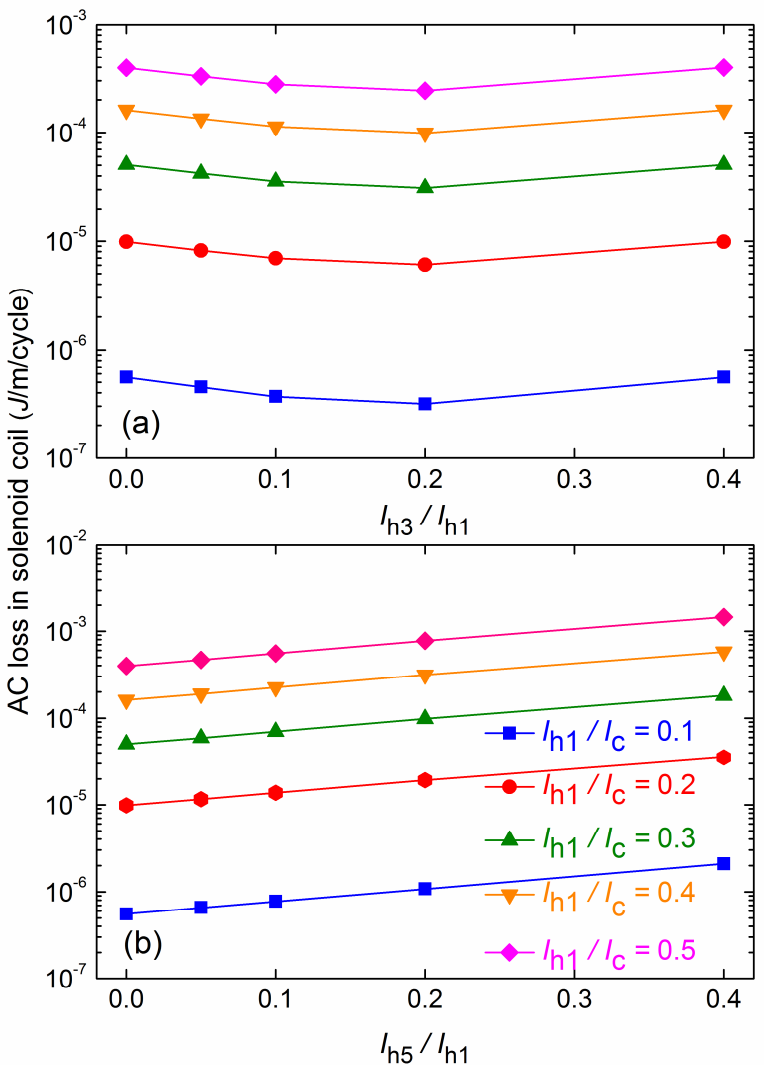

Fig. 10. AC loss results of SNC versus THD carrying distorted current at $I_{\mathrm{h} 1} / I_{\mathrm{c}}$ ranges from 0.1 to 0.5 . (a) carrying the $3^{\text {rd }}$ harmonic (b) carrying the $5^{\text {th }}$ harmonic

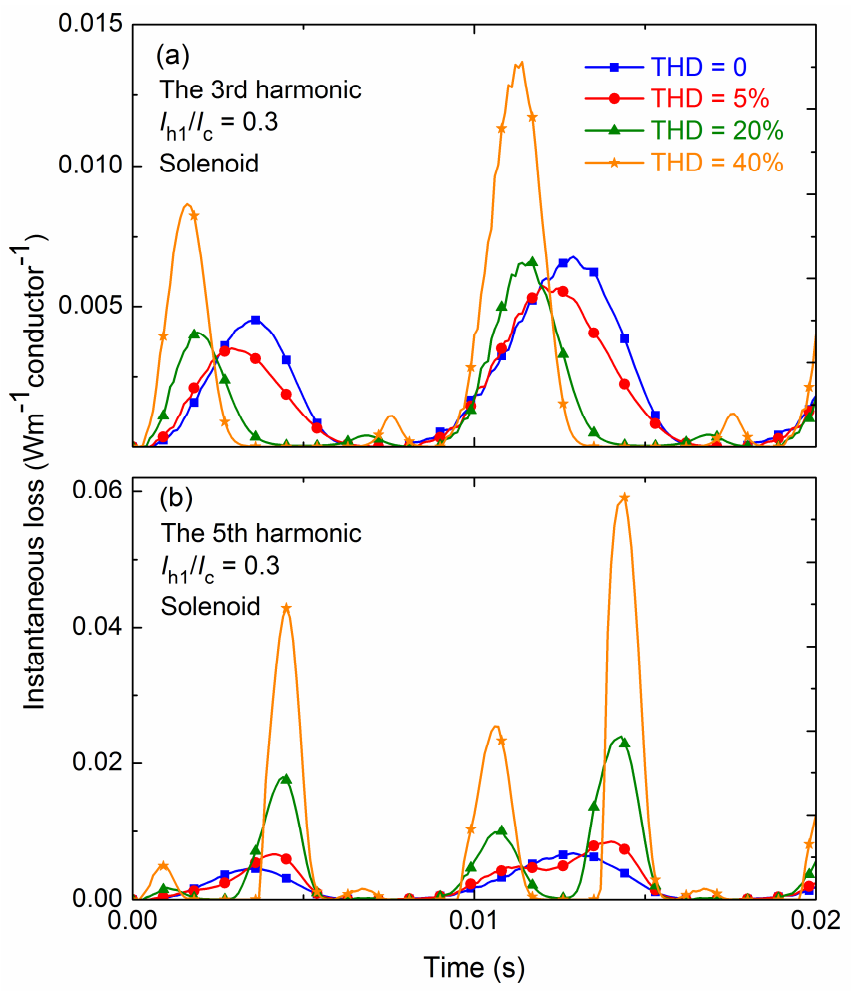

Fig. 11. Instantaneous $\mathrm{AC}$ loss in SNC carrying distorted current at $I_{\mathrm{h} 1} / I_{\mathrm{C}}=0.3$ and different THDs. (a) with $3^{\text {rd }}$ harmonic (b) with $5^{\text {th }}$ harmonic 


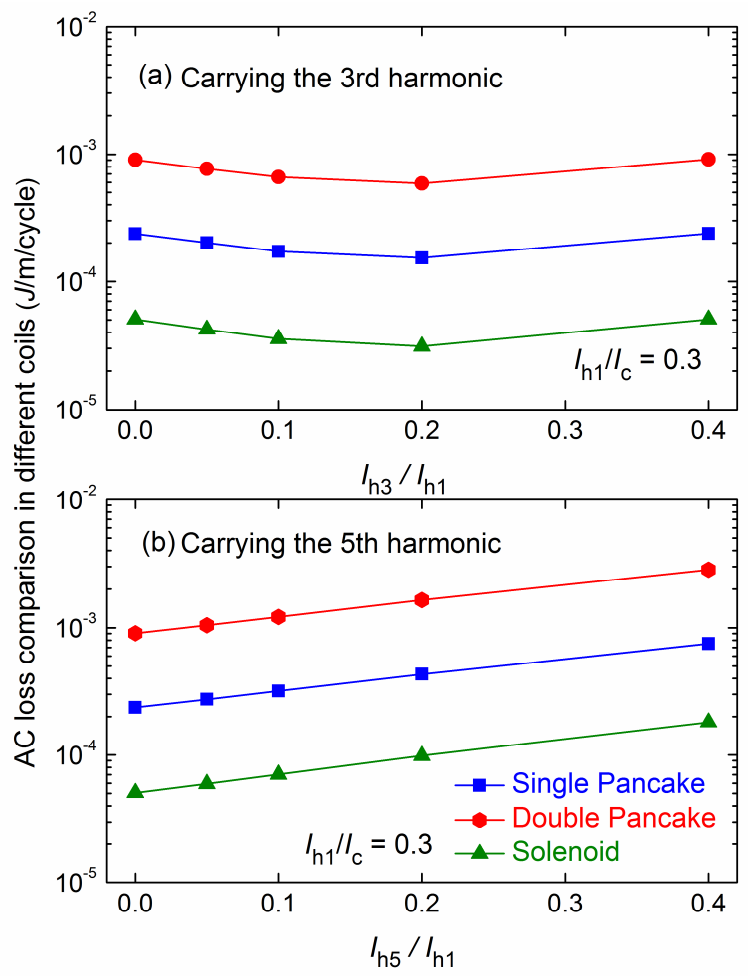

Fig. 12. AC loss comparison among SPC, DPC and SNC carrying distorted current with different THD, at $I_{\mathrm{h} 1} / I_{\mathrm{c}}=0.3$. (a) with the $3^{\text {rd }}$ harmonic (b) with the $5^{\text {th }}$ harmonic.

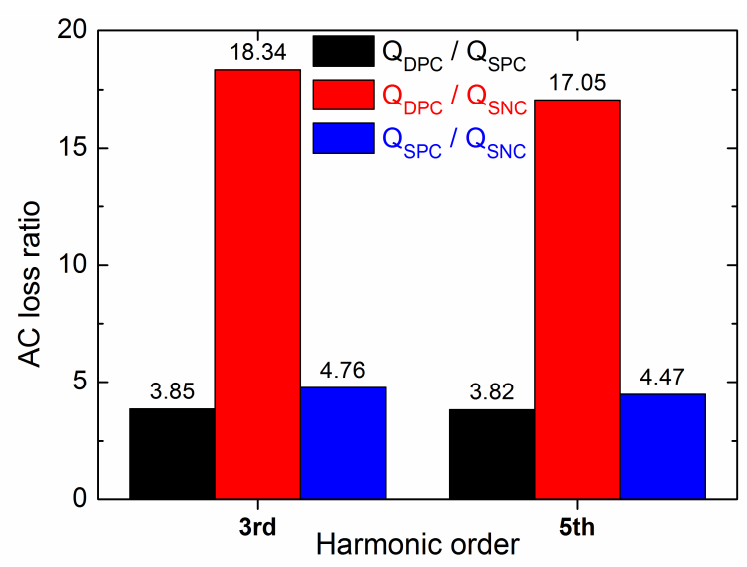

Fig. 13. Comparison of average nonsinusoidal AC loss ratio among SPC, DPC and SNC carrying distorted current vs THD, at $I_{\mathrm{h} 1} / I_{\mathrm{c}}=0.3$. (a) with $3^{\text {rd }}$ harmonic (b) with $5^{\text {th }}$ harmonic.

There are two and three dominant peaks in instantaneous AC loss for the $3^{\text {rd }}$ and the $5^{\text {th }}$ harmonics, respectively, showing similar behavior as seen in Fig. 4 and 8. As it is depicted in Fig. 11 , the maximum peak of the $5^{\text {th }}$ harmonic are $4 \mathrm{x}$ higher than that with the $3^{\text {rd }}$ harmonic. In addition, the peaks of instantaneous loss increases by the increase of THD, monotonically, while in case of the $3^{\text {rd }}$ harmonic, when THD increases, the peaks meet a minimum at THD $=5 \%$.

\section{Discussions: Nonsinusoidal AC loss comparison among pancake coils and SNC}

The pancake and solenoid coils are commonly used coils for fabricating HTS windings in superconducting electrical machines. It should be mentioned that even in case of using racetrack coil in some applications, still it would be modeled the same as DPC in 2D FE calculation. Therefore, the findings of this paper would be useful for a wide range of different large scale devices such as electrical machines, transformers, and some types of fault current limiters for different range of applications from power network to electric aircraft applications. In all aforementioned applications, AC loss estimation is crucial for thermal stability of cooling systems and its efficiency as well as sizing of the device. Knowing this fact makes the topic of this paper important for AC loss analysis during design stage. These findings help the researcher to have a better idea and understanding, when they choose the type of coils in windings for their applications in harmonic polluted environment.

Generally speaking, the peak of the nonsinusoidal currents while carrying $3^{\text {rd }}$ harmonic with $\mathrm{THD}_{3}=5 \%, 10 \%, 20 \%$ are less than the peak of sinusoidal current. But, for $\mathrm{THD}_{3}=40 \%$, more than one peaks with almost similar amplitude to sinusoidal one can be observed. While in case of $5^{\text {th }}$ harmonic, the peak of nonsinusoidal current is always higher than sinusoidal one and that is why AC loss is increasing monotonically. This loss is absolutely hysteretic in nature. The direct effect of harmonics would be reflected in the waveform of the carrying current. The harmonics changes the number of peaks as well as their amplitudes, and as a consequences, the AC loss of the coils.

AC loss comparison among SPC, DPC, and SNC carrying nonsinusoidal currents versus different THDs of the $3^{\text {rd }}$ and the $5^{\text {th }}$ harmonics are depicted in Fig. 12, at $I_{\mathrm{h} 1} / I_{\mathrm{c}}=0.3$. Though wire length of SPC and SNC are identical, AC loss in SPC carrying either $3^{\text {rd }}$ or $5^{\text {th }}$ harmonics is higher than that in SNC. AC loss in SPC carrying the $3^{\text {rd }}$ harmonic with $I_{\mathrm{h} 3} / I_{\mathrm{h} 1}=0.2$ at $I_{\mathrm{h} 1} / I_{\mathrm{c}}=0.3$ is about 5 times of that in SNC. AC loss in SPC carrying the $5^{\text {th }}$ harmonic with $I_{\mathrm{h} 5} / I_{\mathrm{h} 1}=0.2$ at $I_{\mathrm{h} 1} / I_{\mathrm{c}}=0.3$ is 4.4 times of that in SNC. This is due to stronger superposition of radial magnetic field in pancake coils compared to SNC which has a much longer coil height. For the $3^{\text {rd }}$ and $5^{\text {th }}$ harmonics, losses in DPC is highest and the losses of SNC is lowest. It is because radial magnetic flux density is the strongest in DPC with more turns compared to SPC or SNC. Generally, the AC loss versus THD meets a minimum in case of the $3^{\text {rd }}$ harmonic but it is uniformly increasing in case of the $5^{\text {th }}$ harmonic. AC loss in three coils carrying the $5^{\text {th }}$ harmonic in each single THD is $3 x$ to $5 x$ higher than the $3^{\text {rd }}$ harmonic case.

Fig. 13 illustrates the ratio of AC loss for different harmonic orders, in DPC carrying distorted current respect to that in SPC, $Q_{\mathrm{DPC}} / Q_{\mathrm{SPC}}$, the ratio of AC loss in DPC respect to that in SNC, $Q_{\mathrm{DPC}} / Q_{\mathrm{SNC}}$, and also the ratio of AC loss in SPC to that in SNC, $Q_{\mathrm{SPC}} / Q_{\mathrm{SNC}}$. The average AC loss ratio between DPC and SNC is the highest, up to 18.34 and the average ratio between DPC and SPC is the lowest, down to 3.82. We also observed the ratio between AC losses when current distorted by the $3^{\text {rd }}$ harmonic is slightly higher than that with the $5^{\text {th }}$ harmonic.

By comparing the instantaneous AC loss profiles of different coils, several conclusions can be summarized as follow:

1) Two and three dominant peaks appear in instantaneous $A C$ loss in different coils, transporting the $3^{\text {rd }}$ and the $5^{\text {th }}$ harmonic, respectively, as well as three and four much smaller peaks. Therefore, the number of peaks can be formulized as $(h+2)$, as $h$ is harmonic order, or if assumes $h=2 k-1$, therefore, number of total peaks would be counted as ( $2 k+1)$ for $k=1,2$. 
(a) $B_{r}$ distribution in SPC
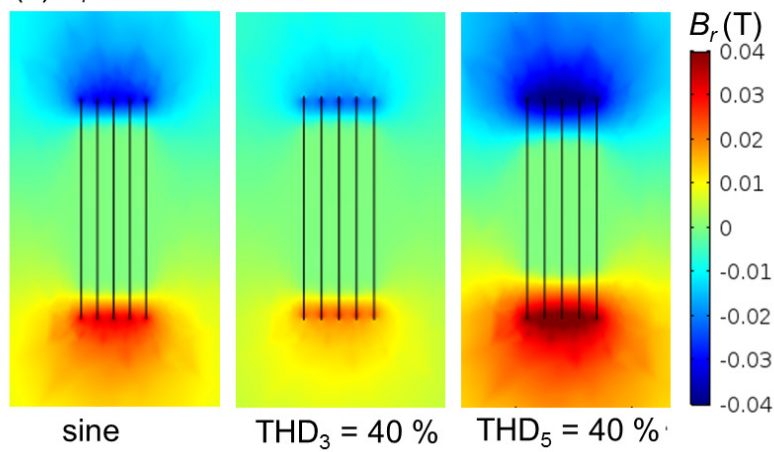

(b) $B_{r}$ distribution in DPC
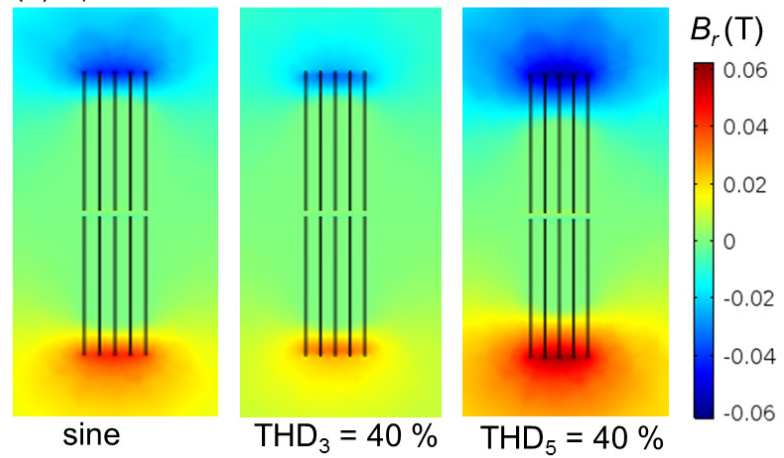

(c) $B_{r}$ distribution in SNC
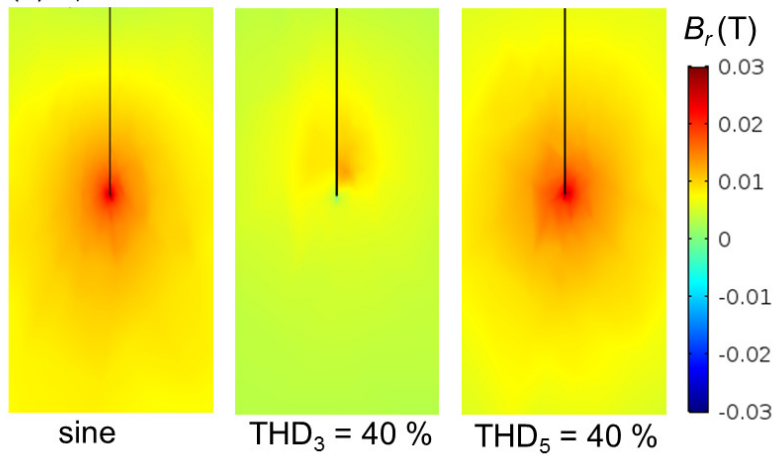

Fig. 14. Comparison of radial magnetic flux density among SPC, DPC and SNC carrying distorted current, at $I_{\mathrm{h} 1} / I_{\mathrm{c}}=0.5$.

2) The amplitude of peaks in instantaneous AC loss profile of different coils in case of the $5^{\text {th }}$ harmonic is 3 to 5 times higher than the $3^{\text {rd }}$ harmonic ones.

3 ) The peaks in case of $5^{\text {th }}$ harmonics are always monastically increasing versus THD i.e. $\mathrm{Q}_{40 \%}>\mathrm{Q}_{20 \%}>\mathrm{Q}_{5 \%}>\mathrm{Q}_{\text {sin, }}$, while in case of $3^{\text {rd }}$ harmonics, it meets a minimum, i.e. $\mathrm{Q}_{40 \%}>\mathrm{Q}_{20 \%}>$ $\mathrm{Q}_{\sin }>\mathrm{Q}_{5 \%}$.

Fig. 14(a), 14(b) and 14(c) compares the radial magnetic flux density $B_{\mathrm{r}}$ distribution in SPC, DPC and end part of SNC, carrying sinusoidal current, current with $\mathrm{THD}_{3}=40 \%$ and $\mathrm{THD}_{5}=40 \%$, respectively, at $t=0.015 \mathrm{~s}$ and $I_{\mathrm{h} 1} / I_{\mathrm{c}}=0.3$. In Fig. 14(a), strong radial magnetic field mainly locates at the end part of the coil, and the maximum radial magnetic flux density in SPC occurs when SPC is carrying the non-sinusoidal current with $\mathrm{THD}_{5}=40 \%$; The peak radial magnetic flux density in SPC carrying current with $\mathrm{THD}_{3}=40 \%$ is bigger than that when carrying sinusoidal current, since the current amplitude with
$\mathrm{THD}_{3}=40 \%$ is smaller than that with sinusoidal current. Similar phenomenon has been observed in Fig. 14(b) and 14(c). On the other hand, at each identical carrying current, the highest and lowest radial magnetic flux density occurs in DPC and $\mathrm{SNC}$, which is aligned with the AC loss tendency.

\section{CONCLUSION}

In this paper, we modeled three superconducting coils with 4-mm wide SuperPower wire, five-turn SPC, five-turn DPC and five-turn SNC, where SPC and solenoid have the same wire length and all three coils share the same inner diameter of 80 $\mathrm{mm}$. AC loss in these three HTS coils carrying the $3^{\text {rd }}$ and $5^{\text {th }}$ current harmonics with THD ranging from $0 \%$ to $40 \%$ at fundamental current ranging from $0.1 \underline{I}_{\mathrm{c}}$ to $0.5 I_{\mathrm{c}}$ have been calculated using $H$-formulation in COMSOL Multiphysics.

There is similar AC loss behavior in three coils when the transport current is distorted by the $3^{\text {rd }}$ harmonic, i.e. AC loss always reaches the minimum at $I_{\mathrm{h} 3} / \mathrm{I}_{\mathrm{h} 1}=20 \%$, with $I_{\mathrm{h} 1} / I_{\mathrm{c}}$ varying from 0.1 to 0.5 . When $0 \%<I_{\mathrm{h} 3} / \mathrm{I}_{\mathrm{h} 1}<20 \%$, AC loss in HTS coils decreases with the increase of the $3^{\text {rd }}$ harmonic content. When $20 \%<I_{\mathrm{h} 3} / \mathrm{I}_{\mathrm{h} 1}<40 \%$, AC loss in HTS coils increases with the increase of the $3^{\text {rd }}$ harmonic content.

AC loss in three HTS coils carrying the $5^{\text {th }}$ harmonic increases monotonically and uniformly with the increase of $I_{\mathrm{h} 5} / \mathrm{I}_{\mathrm{h} 1}$, when $0 \%<I_{\mathrm{h} 5} / \mathrm{I}_{\mathrm{h} 1}<40 \%$, and $0.1<I_{\mathrm{h} 1} / I_{\mathrm{c}}<0.5$.

AC loss in SPC carrying the $3^{\text {rd }}$ harmonic and the $5^{\text {th }}$ harmonic at different THD are more than 3.8 times of that in DPC. While AC loss in SPC carrying either $3^{\text {rd }}$ or $5^{\text {th }}$ harmonics at different THD are around 4.5 times of that in SNC, even SPC and SNC share the same wire length.

Though wire length of SPC and SNC are identical, AC loss in SPC carrying either the $3^{\text {rd }}$ or $5^{\text {th }}$ harmonic with $0 \%<\mathrm{THD}<40 \%$ is more than 3 times higher than that in SNC due to strong radial magnetic field superposition.

\section{REFERENCES}

[1] M. P. Staines, Z. Jiang, N. Glasson, R. G. Buckley, and M. Pannu, "Hightemperature superconducting (HTS) transformers for power grid applications," Superconductors in the Power Grid: Materials and Applications, Elsevier, pp. 367-397, 2015.

[2] M. Yazdani-Asrami, M. Staines, G. Sidorov, M. Davies, J. Bailey, N. Allpress, N. Glasson, and S. Asghar Gholamian, "Fault current limiting HTS transformer with extended fault withstand time," Superconductor Science and Technology, vol. 32, no. 3, pp. 1-13, 2019.

[3] D. Larbalestier, A. Gurevich, D. M. Feldmann, and A. Polyanskii, "HighTc superconducting materials for electric power applications," Nature, vol. 414, no. 6861, pp. 368-377, 2001.

[4] M. Yazdani-Asrami, M. Mirzaie, and A. Akmal, "Investigation on Impact of Current Harmonic Contents on the Distribution Transformer Losses and Remaining Life," 2010 IEEE International Conference on Power and Energy (PECon 2010), pp. 689-694, 2010.

[5] M. Yazdani-Asrami, M. Mirzaie, and A. Akmal, "No-load loss calculation of distribution transformers supplied by nonsinusoidal voltage using three dimensional finite element analysis," Energy, vol. 50, pp. 205-219, 2013.

[6] H. Liu, G. Song, C. Zhang, J. Tan, and W. Feng, "Experimental and Simulation Research of AC Ripple Losses in a High Temperature Superconductor Tape," Advances in Condensed Matter Physics, vol. 2018, pp. 1-5, 2018.

[7] B. Douinc, J. Leveque, A. Rezzoug, "AC loss Measurements of a High Critical Temperature Superconductor Transporting Sinusoidal or Nonsinusoidal Current," IEEE Transactions in Applied Superconductivity, vol. 10, no. 1, pp. 1489-1492, 2000. 
[8] M. Yazdani-Asrami, S. Asghar Gholamian, S. M. Mirimani, and J. Adabi, "Calculation of AC Magnetizing Loss of ReBCO Superconducting Tapes Subjected to Applied Distorted Magnetic Fields," Journal of Superconductivity and Novel Magnetism, vol. 31, no. 12, pp. 3875-3888, 2018.

[9] V. Sokolovsky, V. Meerovich, M. Spektor, G. A. Levin, and I. Vajda, "Losses in Superconductors Under Nonsinusoidal Currents and Magnetic Fields," IEEE Transactions in Applied Superconductivity, vol. 19, no. 3, pp. 3344-3347, 2009.

[10] M. Spektor, V. Meerovich, V. Sokolovsky, and L. Prigozhin, "AC losses in thin coated conductors under nonsinusoidal conditions," Superconductor Science and Technology, vol. 25, no. 2, pp. 1-10, 2012.

[11] M. Tsuda, Y. Nakaide, D. Miyagi, and T. Hamajima, "Estimation Method of AC Losses in HTS Tape Against a Distorted Current and/or a Distorted Magnetic Field With Harmonic Components," IEEE Transactions in Applied Superconductivity, vol. 25, no. 3, pp. 1-5, 2015.

[12] B. J. H. de Bruyn, J. W. Jansen, and E. A. Lomonova, "AC losses in HTS coils for high-frequency and nonsinusoidal currents," Superconductor Science and Technology, vol. 30, no. 9, pp. 1-8, 2017.

[13] Z. Zhu, Y. Wang, S. Venuturumilli, J. Sheng, M. Zhang, and W. Yuan, "Influence of Harmonic Current on Magnetization Loss of a Triaxial CORC REBCO Cable for Hybrid Electric Aircraft," IEEE Transactions in Applied Superconductivity, vol. 28, no. 4, pp. 1-5, 2018.

[14] B. Shen, C. Li, J. Geng, X. Zhang, J. Gawith, J. Ma, Y. Liu, F. Grilli, and T. A. Coombs, "Power dissipation in HTS coated conductor coils under the simultaneous action of AC and DC currents and fields," Superconductor Science and Technology, vol. 31, no. 7, pp. 1-12, 2018.

[15] B. Shen, C. Li, J. Geng, Q. Dong, J. Ma, J. Gawith, K. Zhang, Z. Li, J. Chen, W. Zhou, X. Li, J. Sheng, Z. Li, Z. Huang, J. Yang, and T. A. Coombs, "Power Dissipation in the HTS Coated Conductor Tapes and Coils Under the Action of Different Oscillating Currents and Fields," IEEE Transactions in Applied Superconductivity, vol. 29, no. 5, pp. 1-5, 2019.

[16] S. Dai, W. Zhou, T. Zhang, B. Shen, Y. Liu, X. Yan, Y. Wang, and J. Fang, "AC Loss Analysis of High-Temperature Superconducting Current Leads With Nonsinusoidal Current Waveform," IEEE Transactions in Applied Superconductivity, vol. 29, no. 2, pp. 1-4, 2019.

[17] W. Song, J. Fang, Z. Jiang, M. Staines, and R. Badcock, “AC Loss Effect of High-Order Harmonic Currents in a Single-Phase 6.5 MVA HTS Traction Transformer," IEEE Transactions in Applied Superconductivity, vol. 29, no. 5, pp. 1-5, 2019.

[18] W. Song, J. Fang, and Z. Jiang, "Numerical AC Loss Analysis in HTS Stack Carrying Nonsinusoidal Transport Current," IEEE Transactions in Applied Superconductivity, vol. 29, no. 2, pp. 1-5, 2019.

[19] V. M. Rodriguez-Zermeno, N. Mijatovic, C. Træholt, T. Zirngibl, E. Seiler, A. B. Abrahamsen, N. F. Pedersen, and M. P. Sørensen, "Towards Faster FEM Simulation of Thin Film Superconductors: A Multiscale Approach," IEEE Transactions in Applied Superconductivity, vol. 21, no. 3, pp. 3273-3276, 2011.

[20] S. C. Wimbush, and N. M. Strickland, "A public database of high temperature superconductor critical current data," IEEE Transactions in Applied Superconductivity, vol. 27, no. 4, pp. 1-5, 2017 